\title{
Surgical Thrombectomy in an 81-Year-Old Patient with Right Atrial Thrombus and Pulmonary Embolism
}

\author{
Sağ Atriyal Trombüsü ve Pulmoner Embolisi Olan 81 Yaşındaki Hastada Cerrahi \\ Trombektomi
}

İhsan Alur', İ. Doğu Kılıç2, Fahri Adalı, Hayati Taştan'1, Tevfik Güneş', İbrahim Gökşin'

'Department of Cardiovascular Surgery, Pamukkale University Faculty of Medicine, Denizli, Turkey 2Department of Cardiology, Pamukkale University Faculty of Medicine, Denizli, Turkey

${ }^{3}$ Department of Cardiovascular Surgery, Afyon Kocatepe University Faculty of Medicine, Afyon, Turkey

\section{ABSTRACT}

Introduction: Right atrial thrombus carries a potential risk for pulmonary embolism; 3\%-23\% of patients with acute pulmonary embolism have mobile thrombus, and treatment should be started immediately once a diagnosis is made. In patients with acute pulmonary embolism, medical and surgical methods of treatment can be applied.

Case Report: In this report, we had an 81-year-old patient who presented with sudden onset of shortness of breath, tachycardia, and tachypnea. Echocardiography showed thrombus in the right atrium and another one in the pulmonary trunk at the site of the bifurcation. The patient underwent surgical thrombectomy, with resolution of symptoms.

Conclusion: In conclusion, acute pulmonary embolism is a lifethreatening medical emergency condition that when diagnosed early intervention is necessary.

Keywords: Right atrium, pulmonary embolism, surgical thrombectomy Received: 21.03.2014

Accepted: 27.05.2014

\section{ÖZET}

Giriş: Sağ atriyumda trombüs varlığı pulmoner emboli için potansiyel risk taşır. Akut pulmoner embolili hastaların \%323'ünde serbest (hareketli) trombüs görülebilir. Tespit edildiğinde hemen tedavi başlatılmalıdır. Akut pulmoner embolili hastalarda medikal ya da cerrahi tedavi yöntemleri uygulanabilir.

Olgu Sunumu: Bu yazıda ani başlayan solunum güçlüğü, taşipne, taşıkardi nedeniyle yapılan transtorasik ekokardiyografide sağ atriyumda trombüs ve ana pulmoner arter bifurkasyonunda lokalize trombüs saptanan, cerrahi tromboembolektomi yaptığımız 81 yaşında olguyu sunmak istedik.

Sonuç: Sonuç olarak akut pulmoner emboli yaşamı tehdit eden ve tanı konduğunda erken müdahale gerektiren tıbbi acillerdendir.

Anahtar Kelimeler: Sağ atriyum, pulmoner embolizm, cerrahi trombektomi

Geliş Tarihi: 21.03.2014 Kabul Tarihi: 27.05.2014

\section{Giriş}

Akut pulmoner emboli (PE) dünya genelinde üçüncüen sıkölüm nedenidir. 90 gün içindegerçekleşen tüm ölümlerin \%17,4'ünden sorumludur (1). Tanı konduğunda erken müdahale gerektirir. Tedavi seçenekleri; cerrahi, antikoagülan ve trombolitik tedaviyi içerir. Akut PE tanısı konan hastalara mutlaka transtorasik ekokardiyografi (TTE) yapılmalıdır. PE'li hastaların \%3 ila \%23'ünde, ekokardiyografi ile sağ atriyumda (RA) trombüs tespit edilir. RA'daki trombüs hareketsiz (yapışık) veya hareketli (serbest) olabilir. Avrupa Ekokardiyografi Çalışma Grubuna göre sağ atriyal trombüsler Tip A, B ve C olmak üzere 3 grupta sınıflanır. Tip A trombüs sarmal şekilde (worm-like) ve sıklıkla atriyumda yüzer pozisyondadır (free floating), derin venöz orijinli olup olası PE kaynağıdır (emboli in transit). Tip A trombüse \%98 oranında PE de eşlik eder. Tip B trombüs immobildir ve primer kardiyak orijinlidir. Tip C 


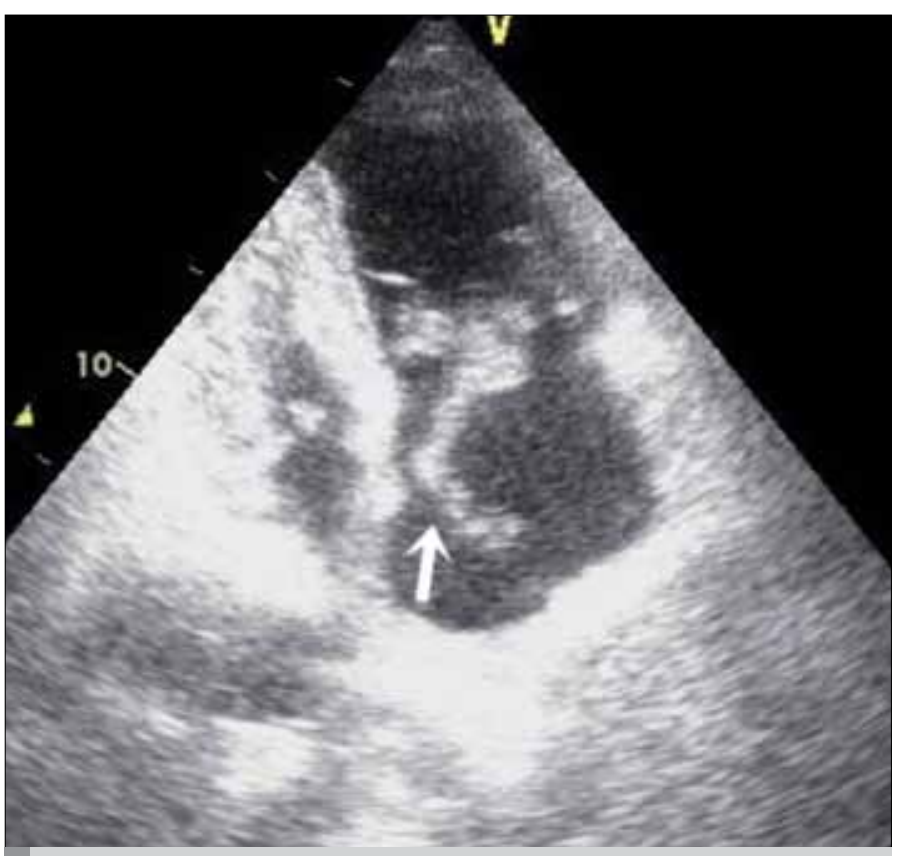

Resim 1. TTE'de RA'da trombüs $(2 \times 0,5 \mathrm{~cm})$ materyali (beyaz ok)

trombüs ise bu iki grupta sınıflanamayan diğer atriyal trombüsleri kapsar (2). Hareketli trombüsün embolizasyon riski daha fazladır. TTE'de sağ atriyumda hareketli trombüs tespit edilen hastalarda 24 saat içinde mortalite hızı \%20'dir (3).

Bizim hastamızda 1 hafta önce geçirilmiş operasyon öyküsü olduğundan trombolitik tedavi kontrendikeydi. Bu nedenle cerrahi tromboembolektomi uygulandı. Hasta komplikasyonsuz eksterne edildi.

\section{Olgu Sunumu}

Seksen bir yaşında kadın 1 hafta önce komplike umblikal herni nedeniyle opere edilmişti. Genel cerrahi servisinde yatmakta olan ve belirgin derin venöz tromboz kliniği olmayan hastada ani başlayan dispne, taşipne (20/dk), hipotansiyon $(80 / 50 \mathrm{mmHg})$, taşikardi (130/dk) gelişti. Parmak ucundan bakılan transkutanöz oksijen saturasyonu düşüktü ( $\mathrm{SpO}_{2}$ : \%80) EKG: sinüs ritmi, ortalama Pulmoner Arter Basıncı (OPAB): 80 mmHg, kan gazında $\mathrm{pH}: 7,46$, $\mathrm{pCO}_{2}: 29, \mathrm{pO}_{2}: 46, \mathrm{O}$, satürasyonu \%83 idi. TTE'de sağ atriyumda 2x0,5 ebatında trombüs (Resim 1) ve ana pulmoner arter bifurkasyonunda lokalize, 4×2 cm ebatında trombüs saptandı. Diğer kalp boşluklarında patolojik görünüm saptanmadı. Kalp kapakları normaldi. Hastanın hemodinamisi giderek kötüleştiği için pulmoner BT anjiografi yapılamadı. Postoperatif dönemde yapılan alt ekstremite venöz Dopler Ultrasonunda trombüs saptanmadı. Latex immünoassay yöntemiyle bakılan D-dimer yüksek: 2885 ng/mL (Referans aralığı: 0-243 ng/mL), kardiyak enzimler hafif yüksek (troponin: 1,6 ng/ $\mathrm{mL}$, miyoglobin: $87 \mathrm{ng} / \mathrm{mL}$, CK-MB: 7,4 ng/mL), Hct: \%31, WBC: 10.200, trombosit: 123.000 idi. Hasta acil olarak operasyona alındı. Operasyon masasına supin pozisyonunda yatırıldı. Genel anestezi altında endotrakeal entübasyon sağlandı. Santral venöz kateterizasyon yapıldı. Operasyon bölgesi betadinle dezenfekte edildi. Steril cerrahi örtü ile örtüldü. Median sternotomiyi takiben aortobikaval kanülasyon yapılarak kardiyopulmoner baypas'a girildi. Normotermide çalışan kalpte önce sağ atriyotomi ile trombektomi uygulandı. Sonrasında Iongitudinal arteriyotomi ile pulmoner embolektomi yapıldı. İşlem tamamlandıktan sonra kardiyopulmoner baypastan sorunsuz çıkıldı ve hastanın yoğun bakıma transferi sağlandı. Postoperatif 2. saatte kan gazı değerleri $\mathrm{pH}$ : 7,49, $\mathrm{pCO}_{2}$ : $35,6, \mathrm{pO}_{2}: 94, \mathrm{O}_{2}$ satürasyon \%97 idi. Hasta postoperatif 16.saatte ekstübe edildi. Ekstübasyon sonrası yapılan ekokardiografide PAB'nın 80 mmHg'dan 32 mmHg'ya düştüğü saptandı. Hastanın kliniği tamamen düzeldi. Çıkarılan materyal patolojik incelemede trombüs olarak raporlandı. Hasta sorunsuz taburcu edildi.

\section{Tartışma}

PE'de ortalama mortalite \%2,5 iken, RA'da trombüs varlığında mortalite \%45'e kadar yükselmektedir (4). PE ile komplike olmuş sağ atriyal trombüsün tedavisi medikal veya cerrahidir. Bu konuda kesin bir görüş birliği yoktur, ancak pulmoner tromboemboli ile birlikte sağ atriyumda serbest yüzen trombüs (Tip A) varsa sistemik trombolitik tedavi uygun bir tercihtir.

Son yıllarda kullanılan alternatif bir tedavi yöntemi de kateter aracılı ultrasonla hızlandırılmış trombolitik tedavi uygulamasıdır. Engelhardt ve ark. masif ya da submasif pulmoner emboli nedeniyle ultrasonla hızlandırımış trombolizis (EKOS: EkoSonic Endovascular System) ile tedavi ettikleri hastalarla ilgili retrospektif çalışmada tüm hastalarda uygulamadan 2-3 saat sonra semptomların dramatik olarak düzeldiğini, hiçbir hastada intraserebral hemoraji veya sistemik kanama görülmediğini, bir hastada tekrarlayan PE görülmesi dışında herhangi bir komplikasyon kaydedilmediğini bildirmişlerdir (5). Olgumuzun 1 hafta önce komplike umblikal herni nedeniyle operasyon öyküsü ve sağ atriyal trombüs birlikteliğinden dolayı cerrahi uyguladık.

Kalp boşluklarında fikse olmuş dev trombüsler (Tip B) için embolektomi önerilmektedir. Pulmoner embolektomi, sistemik arteriyel hipotansiyon ya da sağ kalp yetersizliğine yol açan ve trombolitik tedaviye rağmen ilk bir saat içinde hemodinamisi düzelmeyen veya trombolitik tedavi kontrendikasyonu olan masif PE olgularına uygulanır. Türk Toraks Derneği'nin 2010'da yayınladığı Ulusal Venöz Tromboembolizm Profilaksi ve Tedavi Kılavuzu'nda akut PE için cerrahi embolektomi endikasyonları, akut masif PE'li trombolitik tedavi kontrendikasyonu bulunan ve trombolitik tedaviye yanıt vermeyen hastalar olarak belirtilmiştir (6). Genellikle bu hastalar genel durumu ciddi, komorbiditesi olan olgulardır. Açık cerrahi işlemin temel hedefi, pulmoner kan akımının tamamen düzeltilmesi ve pulmoner arter basıncının normale döndürülmesidir. Pulmoner embolektomi veya tromboendarterektomi kronik tromboembolik pulmoner hipertansiyona gidişi azaltır ve pulmoner hemodinamiyi düzelterek egzersiz kapasitesini artırır $(7,8)$. Sunar ve ark. 64 olguluk serilerinde, Hazan ve ark. pulmoner embolektomi ve tromboendarterektomi uyguladıkları 7 olguda sonuçların iyi olduğunu, hastaların fonksiyonel kapasitelerinin (NYHA) iyileştiğini 
ve ortalama PAB'nın 30 mmHg'nın altına çekilmesinin önemini vurgulamışlardır. Sunar ve ark. bu çalışmada \%15,6 erken mortalite (30 günlük) oranı bildirmişlerdir $(9,10)$. Pulmoner embolektomi veya tromboendarterektominin bazı kolmplikasyonları vardır. Bunlar; persistan pulmoner hipertansiyon, reperfüzyon ödemi, pulmoner hemoraji, sepsis, pnömoni, renal yetersizlik, serebrovasküler olay, perikardiyal efüzyon, atriyal fibrilasyon, nodal ritim, düşük kardiyak debi sendromu ve ölümdür.

Sonuç olarak akut pulmoner emboli (PE) yaşamı tehdit eden ve tanı konduğunda erken müdahale gerektiren tıbbi acillerdendir. Akut PE tanısı konan hastalara sağ atrial trombüs açısından mutlaka TTE yapılmalıdır. Trombolitik tedavinin komplikasyonlarına karşılık cerrahi tromboembolektomigeriatrikhastagrubundabaşarıylauygulanabilir.

Informed Consent: Written informed consent was obtained from patients who participated in this case.

Peer-review: Externally peer-reviewed.

Author Contributions: Concept - I.A., I.G.; Design - I.A., F.A.; Supervision - I.D.K.; Materials - I.A., I.G., F.A.; Data Collection and/or Processing - I.A., H.T.; Analysis and/or Interpretation - I.G.; Literature Review - I.A., T.G., H.T.; Writer - I.A., I.G.; Critical Review - I.G., I.D.K.

Conflict of Interest: The authors declared no conflict of interest. Financial Disclosure: The authors declared that this study has received no financial support.

Hasta Onamı: Yazılı hasta onamı bu olguya katılan hastadan alınmıştır.

Hakem Değerlendirmesi: Dış bağımsız.

Yazar Katkıları: Fikir - I.A., I.G.; Tasarım - I.A., F.A.; Denetleme - I.D.K.; Malzemeler - I.A., I.G., F.A.; Veri toplanması ve/veya işlemesi - I.A., H.T.; Analiz ve/veya yorum - I.G.; Literatür taraması - I.A., T.G., H.T.; Yazıyı yazan - I.A., I.G.; Eleştirel İnceleme - I.G., I.D.K.
Çıkar Çatışması: Yazarlar çıkar çatışması bildirmemişlerdir.

Finansal Destek: Yazarlar bu çalışma için finansal destek almadıklarını beyan etmişlerdir.

\section{Kaynaklar}

1. Goldhaber SZ, Visani L, De Rosa M. Acute pulmonary embolism: clinical outcomes in the International Cooperative Pulmonary Embolism Registry (ICOPER). Lancet 1999; 353: 1386-9. [CrossRef]

2. Koenigshausen $E$, Magnusson $K$, Vester EG. Succesful thrombolysis in patient with right heart thromboembolizm. Clin Res Cardiol 2007; 96: 755-8. [CrossRef]

3. Barriales V, Tamargo JA, Aguado MG, Martín M, Rondán J, Segovia E, et al. Floating thrombi on the Eustachian valve as a complication of venous thromboembolic disease. Int J Cardiol 2004; 93: 289-91. [CrossRef]

4. Chartier L, Béra J, Delomez M, Asseman P, Beregi JP, Bauchart JJ, et al. Freefloating thrombi in the right heart: diagnosis, management and prognostic indexes in 38 consecutive patients. Circulation 1999; 99: 2779-83.[CrossRef]

5. Engelhardt TC, Taylor AJ, Simprini LA, Kucher N. Catheter-directed ultrasound-accelerated thrombolysis for the treatment of acute pulmonary embolism. Thromb Res 2011; 128: 149-54. [CrossRef]

6. Arseven $O$, Sevinç $C$, Alataş F ve ark. Türk Toraks Derneği Pulmoner Tromboembolizm Tanı ve Tedavi Uzlaşı Raporu. Türk Toraks Dergisi 2009; 10: 1-46.

7. Yalamanchili K, Fleisher AG, Lehrman SG, Axelrod HI, Lafaro RJ, Sarabu $M R$, et al. Open pulmonary embolectomy for treatment of major pulmonary embolism. Ann Thorac Surg 2004; 77: 819-23. [CrossRef]

8. Mayer E, Jenkins D, Lindner J, D’Armini A, Kloek J, Meyns B, et al. Surgical management and outcome of patients with chronic thromboembolic pulmonary hypertension: results from an international prospective registry. J Thorac Cardiovasc Surg 2011; 141: 702-10. [CrossRef]

9. Hazan E, Şişli E, Uğurlu Ş.B, Akdeniz B, Barış N, Silistreli E. Yedi olguda pulmoner embolektomi ve tromboendarterektomi. Turk Gogus Kalp Dama 2012; 20: 442-9. [CrossRef]

10. Sunar H, Yıldızeli B, Taş $S$ ve ark. Kronik tromboembolik pulmone hipertansiyonda pulmoner endarterektomi. Turk Gogus Kalp Dama 2013; 21: 7-13. [CrossRef] 